\title{
Evolução do Programa Bolsa Família:
} Brasil e estados do Nordeste 2004-2009 / Evolution of the Conditional Cash Transfer Program1: Brazil and northeastern states - 2004-2009*

\author{
Silvana Nunes de QueIroz ${ }^{* *}$ \\ Maria Alice Pestana de Aguiar Remy ${ }^{* * *}$ \\ Júlia Modesto Pinheiro Dias Pereira ${ }^{* * * *}$ \\ Luis Abel da Silva Filho*****
}

Resumo: Este artigo analisa a evolução no número de beneficiários e no valor do repasse do Programa Bolsa Família (PBF). Para tanto, são feitas considerações sobre o conceito de pobreza e as principais alterações na concepção do PBF. O estudo tem como recorte temporal os anos de 2004 a 2009, e recorte espacial o Nordeste brasileiro, região com os piores indicadores sociais e demográficos do país. A fonte de dados foi a Matriz de Informação Social do MDS (Ministério do Desenvolvimento Social), que aponta para a diminuição no número de beneficiários e no valor repassado aos Programas Remanescentes (Auxílio Gás, Cartão Alimentação, Bolsa Alimentação, Bolsa Escola) vis-à-vis a expansão no número de famílias pobres assistidas pelo PBF. Apesar das críticas de alguns setores aos programas de proteção social, em 2008 foram gastos R $\$$ 10,6 bilhões com

\footnotetext{
* Trabalho publicado nos anais do XVII Encontro Nacional de Estudos Populacionais e disponibilizado no sítio http://www.abep.nepo.unicamp.br/encontro2010/docs_pdf/eixo_1/ abep2010_2557.pdf.

** Professora Assistente do Departamento de Economia da Universidade Regional do CaririURCA, Doutoranda em Demografia pelo NEPO/UNICAMP e bolsista FUNCAP. E-mail: silvanaqueirozce@yahoo.com.br

*** Pesquisadora do Cesit/UNICAMP e Doutoranda em Desenvolvimento Econômico pelo IE/ UNICAMP. E-mail: mariaalice.pestana@gmail.com

**** Mestranda em Demografia pelo NEPO/UNICAMP e Bolsista CNPq. E-mail: julia_ modestopdpereira@yahoo.com.br

***** Mestrando em Economia pelo PPGECO-UFRN. Bolsista CAPES e Pesquisador do Observatório das Metrópoles, núcleo da UFRN. E-mail: abeleconomia@hotmail.com
} 
PBF, o equivalente a 0,38\% do PIB desse ano. A expansão desses programas tem possibilitado a melhora nos indicadores sociais do Nordeste, que aos poucos vem diminuindo o "gap" com o restante do país.

Palavras-chave: Transferência de Renda. Bolsa Família. BrasilNordeste.

Abstract: This article focuses on the evolution of the number of selected beneficiaries granted by Brazilian Conditional Cash Transfer Program (Programa Bolsa Família - PBF) as well as on the amount of cash provided. Therefore, considerations about poverty and PBF's main adjustments along the observation period (2004-2009) are presented primarily. Brazil's Northeast region presents the lowest quality in social and demographic indicators and is studied in this paper. The data is used from Matriz, de Informação Social (Ministry of Social Development - MDS). Results suggest a trade off between PBF and Programas Remanescentes (aid to buy gas, to study and Food Scholarship). There was a decrease on the number of beneficiaries and the amounts granted to Programas Remanescentes while the opposite had happened to PBF. Despite criticisms towards the PBF from some groups of the society, the program expenses reached $\mathrm{R} \$ 10,6$ billions, just $0,38 \%$ of the GDP in 2008. Overall, the evidence suggests that $\mathrm{PBF}$ is effective since Northeast's social indicators have improved, shortening the gap among Brazilian regions.

Keywords: Conditional cash transfer programs. Bolsa-Família. Brazil-Northeast.

\section{Introdução}

A pobreza tem sido fonte de preocupação mundial nos últimos anos, tendo lugar de destaque nos projetos da Organização das Nações Unidas (ONU) através de suas agências e de órgãos que tratam de questões específicas, como o Programa das Nações Unidas para o Desenvolvimento (PNUD), a Organização Internacional do Trabalho (OIT), a Organização para a Agricultura 
e a Alimentação (FAO), a Organização Mundial da Saúde (OMS), entre outros.

Em 2000 foi lançada pela Organização das Nações Unidas a Declaração do Milênio. Trata-se de um plano de ação global, com oito objetivos ${ }^{1}$, monitorado por 48 indicadores, a serem alcançados até 2015. Dentre esses objetivos, destaca-se a erradicação da extrema pobreza e da fome em escala mundial (ORGANIZAÇÃO DAS NAÇÕES UNIDAS, 2010).

No início dos anos de 1990, as políticas de combate à pobreza entraram na agenda nacional, com o objetivo, não somente, de erradicar a pobreza, mas também de reduzir as desigualdades sociais e regionais. Uma dessas primeiras iniciativas foi através da proposta do Projeto de Lei da Câmara no 2661 (PLS 80/91), de 1992, que pretendia instituir o Programa de Garantia de Renda Mínima. ${ }^{2}$ Desde então, a promoção social tem se tornado uma das principais prioridades do Governo Federal do Brasil.

Com a estabilidade econômica alcançada em 1994, chegase a baixos níveis de inflação e, juntamente com a introdução e expansão dos programas de transferência de renda para a população considerada de mais baixa renda, amplia-se imediatamente o poder de compra, principalmente da população mais pobre. De certa forma os anos 90 inauguram a temática da questão social no país, ao lançar alguns programas de transferência de renda: 1) o Benefício de Prestação Continuada (1993), que tinha por objetivo transferir a renda de um salário mínimo para os idosos e deficientes físicos que se encontrassem em famílias com renda per capita

Erradicação da pobreza extrema e da fome, promoção da educação básica universal, igualdade entre os sexos e autonomia das mulheres, redução da mortalidade na infância, melhoria da saúde materna, combater o HIV/aids, a malária e outras doenças, garantia da sustentabilidade ambiental, estabelecimento de uma parceria mundial para o desenvolvimento (ORGANIZAÇÃO DAS NAÇÕES UNIDAS, 2010).

2 Vale frisar que a proposta original do senador Eduardo Suplicy (Projeto de Lei n 2.661/1992), quando encaminhada para a Câmara dos Deputados, ficou "engavetada". Na verdade, a proposta do projeto de renda mínima sofreu inúmeras alterações - nove emendas, recebendo parecer favorável da Câmara dos Deputados somente em junho de 1996 (FONSECA, 2000). 
inferior a $1 \frac{4}{4}$ do salário mínimo; 2) o Programa de Erradicação do Trabalho Infantil (1996), que tem por objetivo retirar os menores de 16 anos do trabalho infantil, para isso é oferecida uma renda por criança, que tem o seu valor diferenciado entre áreas urbanas e rurais, além de oferecer serviços de convivência que são realizados no contraturno escolar. Nos anos 2000, assiste-se à implementação e à ampliação de uma rede de proteção social com a criação de inúmeros programas sociais focalizados: como o Bolsa Escola ${ }^{3}$ (2001), Bolsa Alimentação (2001), Auxílio Gás (2002), Cartão Alimentação (2003) e o Bolsa Família (2003).

Ao longo dos anos 2000, os programas de transferência de renda do Governo Federal passaram por inúmeras mudanças quanto ao número de assistidos, o valor do repasse e a cobertura. Com a criação do Ministério do Desenvolvimento Social e Combate à Fome (MDS), em outubro de 2003, assiste-se ao processo de unificação dos programas remanescentes (Auxílio Gás, Bolsa Escola, Bolsa Alimentação e Cartão Alimentação) que migraram para o Programa Bolsa Família. Desde então, este último tem se tornado o programa social de maior visibilidade no país, apesar do Benefício de Prestação Continuada (BPC) liderar o volume de recursos gastos com os programas de transferência de renda.

Esse artigo tem como objetivo analisar a recente evolução no número de beneficiários e no valor do repasse com os Programas Remanescentes e o Programa Bolsa Família (PBF). A análise focase no Brasil e nos estados do Nordeste, em função desta região apresentar os mais elevados níveis de pobreza e contemplar o maior número de inscritos em tais programas. Para tanto, são feitas considerações sobre o conceito de pobreza, principais alterações na concepção desses programas, análise entre a relação do tamanho

\footnotetext{
3 No Brasil, os primeiros programas de transferência de renda foram implantados no município de Campinas-SP e de Ribeirão Preto-SP, no ano de 1995, com o nome de Programa de Garantia de Renda Familiar Mínima (PGRFM). Nesse mesmo ano, foi implantando, no Distrito Federal, o Bolsa Família para a Educação. Veja-se Fonseca (2000) para maiores detalhes.
} 
da população e o tamanho da pobreza, além do acompanhamento das mudanças no número de inscritos e no montante gasto com esses dois programas, entre 2004 a 2009.

\section{Breves considerações sobre o conceito de pobreza}

A discussão conceitual sobre a pobreza e a sua medida tem sido tema para diversas pesquisas e debates mundiais. Fundamentalmente, o assunto se coloca sobre duas bases. A primeira privilegia a insuficiência de renda como critério essencial para a sua determinação e, na segunda concepção, o referencial é o desprovimento de necessidades básicas.

No primeiro enfoque, considera-se uma renda mínima necessária para que o indivíduo alcance um padrão de vida adequado em sua sociedade ou país. No segundo caso, as condições referem-se às necessidades humanas, como nutrição, saúde, habitação e vestuário. Assim, para se mensurar a pobreza de uma sociedade é preciso a priori estabelecer-se um conceito, afinal pobres serão aqueles que, perante a definição escolhida, serão considerados como tal.

A utilização da renda como critério de mensuração da pobreza reside no fato de que nas economias modernas o rendimento é a forma utilizada para aquisição de bens e serviços. Portanto, se insuficiente para alcançar o atendimento das necessidades básicas de um grupo de pessoas, estas seriam classificadas como pobres, justificando o princípio da utilização da renda.

Neste ponto é preciso introduzir o conceito de pobreza absoluta e pobreza relativa. A pobreza absoluta refere-se à incapacidade de um consumo mínimo, enquanto a pobreza relativa está diretamente relacionada aos padrões de uma determinada sociedade. 
Pobreza absoluta está estreitamente vinculada às questões de sobrevivência física; portanto, ao não-atendimento das necessidades vinculadas ao mínimo vital. O conceito de pobreza relativa define necessidades a serem satisfeitas em função do modo de vida predominante na sociedade em questão, o que significa incorporar redução das desigualdades de meios entre indivíduos como objetivo social. Implica, consequentemente, delimitar um conjunto de indivíduos "relativamente pobres" em sociedades onde o mínimo vital já é garantido a todos. (ROCHA, 2005, p. 11)

De acordo com a Declaração das Nações Unidas, a pobreza absoluta é a condição caracterizada por privação severa das necessidades humanas básicas, como alimentação, qualidade da água, rede sanitária, saúde, habitação, educação e informação. Ou seja, não depende apenas da renda, mas também do acesso aos serviços.

Entretanto, há duas críticas principais ao estabelecimento de um conceito na determinação das necessidades básicas de um indivíduo. A própria determinação dessas necessidades já se trata de um conceito relativo conforme alguns autores.

[...] As far as food requirements are concerned, nutritional needs depend in great measure on how active a person is, what kind of climate he or she lives in, the type of housing, and whether the standard is defined to simply ensure prolongation of life or to maintain a given standard of health. The stimulated caloric intake for an adult or woman can vary considerably depending on these factors. Moreover, even given a minimal level of calories, it is possible to fulfill this requirement very cheaply if one could live on potatoes and raw vegetables alone [...] (WOLFF 2009, p. 95)

Wolff (2009) corrobora o desconforto de Rocha (2005), chamando a atenção para um estudo de Rowntree (1901) usado para determinar uma linha de pobreza em York, Inglaterra. O chá era incluído como item essencial na composição de uma cesta mínima, embora seu valor nutricional fosse quase nulo. Portanto, 
a inclusão de itens mínimos reflete os aspectos relativos à uma cultura determinada e em uma época em particular, como é o caso da inclusão de charutos na cesta básica cubana, enquanto ao longo do último quarto do século XX seu consumo tenha sido desestimulado em virtude dos comprovados danos à saúde. A segunda crítica de Wolff (2009) refere-se às alterações do conceito de pobreza absoluta no tempo. Conforme seu estudo, os padrões atuais de pobreza absoluta nos Estados Unidos se aplicados no país em 1880 indicariam que quase toda a população deste país estaria vivendo abaixo da linha de pobreza. Por outro lado, suas estimativas indicam que, em 2090, esta população estaria toda acima da linha de pobreza.

Para minimizar esta problemática, a medida relativa considera um percentual determinado da mediana ou da média, da renda ou do consumo das famílias ou dos indivíduos em uma sociedade ou país. Aqueles abaixo do percentual são considerados abaixo dos padrões e, portanto, pobres.

O estabelecimento de uma linha para definir a pobreza indica também subgrupos populacionais como aqueles que sequer atingem a quantidade de calorias necessárias para a sobrevivência, mesmo com as críticas que vimos anteriormente. Entretanto, seja qual for o princípio utilizado, o objetivo para a formulação de programas sociais é dimensionar o público potencial a ser atendido pelos mesmos. A questão base é tentar incorporar esse grupo de indivíduos, que, a despeito do crescimento econômico, encontram-se e permanecem marginalizados. Trata-se, portanto, de um compromisso que vai além da preocupação política e econômica.

De acordo com Rodrigues et al. (1999), ao se colocar a pobreza enquanto fenômeno social surgem diferentes abordagens teóricas, com destaque para a abordagem socioeconômica, que 
tradicionalmente tem feito uma associação entre pobreza e privação de necessidades básicas como decorrência da escassez de recursos econômicos.

Organismos internacionais como as Nações Unidas e o Banco Mundial começam a promover, a partir da década de 70 do século XX, a disseminação desse objetivo através de incentivo a programas concebidos especificamente na direção de atingir tais grupos e alcançar a evolução social de forma mais abrangente. É preciso destacar que a forma de incorporação também é pauta de debate acadêmico entre "universalistas" e "focalizadores". Os primeiros alegam que o crescimento econômico é o motor para a incorporação, sendo os programas focalizados a um determinado público apenas um paliativo. Ambas as vertentes concordam, entretanto, sobre a importância e os benefícios para este grupo com risco social.

No Brasil, inexiste uma linha de pobreza oficial, entretanto, os pesquisadores associados às instituições públicas que atuam em pesquisa ou combate aos problemas de pobreza utilizam-se dos dados do IBGE (Censo, PNAD e POF) para criar metodologias cujas linhas de corte são definidas no escopo do trabalho. ${ }^{4}$

Ribas chama atenção também para a dimensão demográfica:

o grau de pobreza que uma sociedade experimenta depende tanto do volume e da distribuição de recursos quanto do tamanho, da distribuição e das características da população entre as famílias. Assim, como se sabe, pobreza é uma consequência das condições econômicas e demográficas em determinado período. (RIBAS, 2005, p. 6)

Além do aspecto demográfico, há a preocupação regional. Historicamente, o desenvolvimento econômico brasileiro

4 Veja ROCHA (2005); HOFFMANN (2002); BARROS, HENRIQUES e MENDONÇA (2001). 
privilegiou determinadas áreas em detrimento de outras, incluindo populações e marginalizando outras (Norte e Nordeste). O desenvolvimento regional brasileiro é tema que pode ser encontrado em CANO (1977 e 1985), pesquisador dos motivos da concentração da indústria em São Paulo. Posteriormente, Diniz e Crocco (1996) estudam a perda de participação industrial (e do emprego), ocorrida entre 1970 e 1991 nas duas maiores regiões metropolitanas, São Paulo e Rio de Janeiro. A abertura comercial, financeira e a desregulamentação dos anos 90 teriam induzido a concentração da atividade industrial geograficamente em um "polígono" que partiria do centro de Minas Gerais até o Nordeste do Rio Grande do Sul. Pacheco (1998) aponta para uma problemática regional que até os anos 80 tinha um eixo patrocinador de sinergia que aos 90 vai sendo fraturado a favor de um fortalecimento do regionalismo. Tal percepção indica a fragmentação de um projeto nacional capaz de enfrentar os problemas de desigualdades regionais. A complexidade do comportamento regional, entretanto, continua a apontar para uma situação socioeconômica inferior para as regiões Norte e Nordeste. No mesmo sentido da fragmentação do projeto nacional, Bacelar (2005) chama a atenção para o regionalismo que privilegia apenas aspectos locais associados ao dinamismo internacional.

O regionalismo dos ricos, que negam o chamado Brasil pobre e querem inserir sua "ilha" dinâmica na economia mundial. É a exacerbação de rivalidades e a formação ampliada de bolsões de miséria, tudo apontando para a inviabilização do país como projeto nacional. (ARAUJO, 2005, p. 236)

Assim, os programas de transferência de renda vão ao encontro da minimização dos efeitos da pobreza e risco social da população considerada miserável ou em extrema pobreza. Recentemente, algumas mudanças significativas foram introduzidas nos Programas de Transferência de Renda, assunto que será abordado no próximo item. 


\section{Principais alterações na concepção dos programas de transferência de renda brasileiros}

Em outubro de 2003 foi editada a Medida Provisória no 132 que criou o Programa Bolsa Família. Em janeiro de 2004, quando ocorreu a criação do Ministério do Desenvolvimento Social e Combate à Fome (MDS), essa MP foi transformada na Lei ${ }^{\circ}$ 10.836. Desde outubro de 2003, os diversos programas existentes passaram a ser consolidados em um único, o Programa Bolsa Família, que progressivamente reuniu os beneficiários do Bolsa Escola, Bolsa Alimentação, Cartão Alimentação e Auxílio Gás.

O primeiro deles, o Bolsa Escola, instituído pela Lei $n^{\circ}$ 10.219, de abril de 2001, tinha por objetivo manter as crianças de famílias consideradas pobres na escola. Essas famílias, com crianças de 6 a 15 anos matriculadas no ensino fundamental, tinham direito ao benefício, com no máximo três crianças inscritas no programa. Ele exigia a frequência regular em 90\% das aulas. Tinha por público-alvo todas as famílias com renda per capita inferior a $R \$ 90,00$, sendo o beneficio de $R \$ 15,00$ por criança.

O Programa Bolsa Alimentação, instituído pela Medida Provisória $\mathrm{n}^{\mathrm{o}}$ 2.206-1, em setembro de 2001, tinha por objetivo a melhoria das condições de saúde e nutrição de mães que estivessem amamentando filhos com até seis meses de idade, bem como de crianças com seis meses a seis anos e onze meses de idade, em famílias consideradas de baixa renda. A condicão para a continuidade do recebimento era a participação em ações de saúde, como pré-natal, vacinação, incentivo ao aleitamento materno, entre outras. Participavam deste programa as famílias com renda familiar per capita inferior a meio salário mínimo, e cada família recebia entre $\mathrm{R} \$ 15,00$ e $\mathrm{R} \$ 45,00$.

O Auxílio Gás, instituído pela Medida Provisória no 18 , de dezembro de 2001, foi convertido na Lei no 10.453 , em maio 
de 2002. Subsidiava a compra de botijão de gás para cozinhar e era destinado às pessoas com baixa renda inscritas no Programa Bolsa Escola e no Cadastro Único dos Programas Sociais. Era pago bimestralmente $R \$ 7,50$ para as familias com renda per capita inferior a $\mathrm{R} \$ 90,00$.

O Cartão Alimentação, instituído pela Medida Provisória $\mathrm{n}^{\circ} 108$, de fevereiro de 2003, e regulamentado pelo Decreto $\mathrm{n}^{\circ}$ 4.675 , de abril de 2003 , visava garantir à população em situação de insegurança alimentar recursos financeiros ou o acesso ao alimento em espécie. Quando o alimento fosse em espécie, deveria se respeitar as especificidades da população brasileira. Caso o benefício fosse em dinheiro, era repassado um valor de $\mathrm{R} \$ 50,00$.

O Programa Bolsa Família (PBF), instituído pelo Governo Federal em outubro de 2003, sob a coordenação do Ministério do Desenvolvimento Social e Combate à Fome (MDS), tornase o principal programa deste órgão e para o qual vão sendo migrados aos poucos os beneficiários dos demais programas. A principal justificativa para a unificação é evitar a sobreposição de programas, de maneira a aumentar o número de beneficiados e elevar o benefício pago por família.

Se por acaso ocorresse alguma perda financeira na migração, a família passaria a receber o denominado Benefício Variável de Caráter Extraordinário (BVCE) por tempo determinado. Essa migração foi feita com base na utilização do Cadastro Único (CADÚnico), instituído pela Lei no 3.877, de julho de 2001. Esse cadastro tem como função retratar a situação socioeconômica de todas as famílias de baixa renda, para a inserção delas nos programas sociais, sendo consideradas famílias de baixa renda aquelas com renda familiar mensal de até três salários mínimos, ou renda familiar per capita de meio salário mínimo. Ou seja, visando evitar o desperdício de recursos e a multiplicidade de diferentes 
benefícios concentrados em poucas famílias, o MDS integrou no CADÚnico todas as famílias que seriam potenciais recebedoras de benefícios de transferência de renda.

O público-alvo do Programa Bolsa Família são famílias que estão em situação de extrema pobreza e de pobreza. As famílias em extrema pobreza recebem um benefício básico independente de sua composição familiar, mais o benefício variável, e as famílias em situação de pobreza recebem apenas o benefício variável. Em 2009, as linhas de corte para a definição desses dois grupos eram de $\mathrm{R} \$ 70,00$ e R \$ 140,00, respectivamente. Nesse mesmo ano, o valor básico foi de $R \$ 68,00$ e o valor variável $R \$ 22,00$. Além desses valores, em dezembro de 2007 a MP 411 introduziu o Benefício Variável vinculado ao Adolescente (BVJ), que estendeu o benefício para os jovens de 16 e 17 anos que continuassem matriculados na escola. No ano de 2009, o BVJ era de R $\$ 33,00$.

Em dezembro de 2005, por intermédio da Portaria no 666 do MDS, houve a integração entre o Programa Bolsa Família e o Programa de Erradicação do Trabalho Infantil (PETI). Para evitar a duplicidade e a concorrência de ações governamentais, decidiu-se pela integração dos dois programas. As famílias que faziam parte do PETI passam a fazer parte do Bolsa Família ${ }^{5}$, e as crianças do Bolsa Família que estão em situação de trabalho infantil passam a fazer parte das Ações Socioeducativas e de Convivência operadas pelo PETI.

No tocante as condicionalidades, as famílias beneficiadas com os programas assumem compromissos nas áreas da educação, da saúde e assistência social. $\mathrm{Na}$ área da educação, as exigências são a matrícula e a frequência escolar mínima de $85 \%$ para as crianças e adolescentes entre 6 e 15 anos, frequência mínima de 75\% para adolescentes entre 16 e 17 anos. Na área de saúde, é necessário

\footnotetext{
Quando essa integração implicar em perda de renda para a família, a mesma continuará recebendo pelo PETI. Da mesma forma, quando a renda familiar per capita for superior ao corte de renda do Bolsa Família, ela também continuará a receber pelo PETI.
} 
o acompanhamento do calendário vacinal para as crianças de até 7 anos e o pré-natal das gestantes. $\mathrm{Na}$ assistência social, existem ações socioeducativas para as crianças e adolescentes de até 15 anos em situação de trabalho infantil, a partir de frequência mínima de $85 \%$ na escola. Tais condições visam criar chances para que as famílias superem sua situação de pobreza ou extrema pobreza.

A operacionalização do programa ocorre por meio da utilização do Cadastro Único de Programas Sociais do Governo Federal (CadÚnico). No CADÚnico estão as famílias com renda mensal de até três salários mínimos e apenas as famílias que percebem os recortes de renda exigidos são incluídas no PBF. Mensalmente, são extraídas informações da base de dados, visando a identificação das famílias e de possíveis alterações, como a inclusão de mais um membro no registro de uma família que recebe apenas benefício variável ou mesmo a exclusão daquela família que passa a se tornar inelegível. ${ }^{6}$

Para tratar do universo de potenciais candidatos aos programas de renda, passamos para a próxima seção, que dimensiona o tamanho da pobreza no país.

\section{Tamanho da população e da pobreza no Brasil}

A Tabela 1 apresenta as estimativas da população brasileira e de suas cinco regiões, para o ano de 2009, combinadas com as estimativas do número de famílias pobres ${ }^{7}$, em 2004, segundo o cálculo do Instituto de Pesquisa Econômica Aplicada (IPEA). De

\footnotetext{
6 As famílias se tornam inelegíveis quando elas ultrapassam o valor de renda mensal per capita máximo estabelecido pelo programa. Ou seja, quando a família tem uma renda per capita maior que $R \$ 140,00$, ou, no caso de famílias que recebem apenas o benefício variável, quando os filhos completam 18 anos.

7 Destaca-se que esse artigo não pretende abordar ou discutir o dimensionamento da pobreza a partir dos cálculos do número de pobres feitos pelo Instituto de Pesquisa Econômica Aplicada (IPEA) e pelo Instituto Brasileiro de Geografia e Estatística (IBGE), que divergem no corte da renda.
} 
acordo com o IBGE, em 2009 a população estimada do Brasil seria de 191.481.045 habitantes. Por sua vez, em 2004, o IPEA estimou que o país tivesse 11.102.763 de famílias pobres. Assim, ao considerar o tamanho médio da família brasileira, composta por quatro indivíduos, tem-se aproximadamente 44,5 milhões de pobres, algo em torno de $23,22 \%$ da população do país.

\section{Tabela 1 - Estimativa da população e famílias pobres, segundo grandes regiões Brasil - 2009}

\begin{tabular}{|c|c|c|c|c|}
\hline Região & $\begin{array}{c}\text { Estimativa da } \\
\text { População em } \\
\text { 2009 }\end{array}$ & $\begin{array}{c}\text { Estimativa } \\
\text { de Famílias } \\
\text { Pobres (IPEA } \\
\text { 2004) }\end{array}$ & $\begin{array}{c}\text { \% } \\
\text { Estimativa } \\
\text { da } \\
\text { População } \\
\text { em 2009 }\end{array}$ & $\begin{array}{c}\text { \% da Estimativa } \\
\text { de Pobres* (IPEA } \\
\text { 2004) em Relação } \\
\text { à Estimativa da } \\
\text { População Total Pobre } \\
\text { (2004) }\end{array}$ \\
\hline Norte & 15.359 .645 & 1.083 .681 & 8,02 & 9,76 \\
\hline Nordeste & 53.591 .299 & 5.499 .039 & 27,99 & 49,53 \\
\hline Sudeste & 80.915 .637 & 2.995 .750 & 42,26 & 26,98 \\
\hline Sul & 27.718 .997 & 927.034 & 14,48 & 8,35 \\
\hline Centro-Oeste & 13.895 .467 & 597.259 & 7,26 & 5,38 \\
\hline Total & $\mathbf{1 9 1 . 4 8 1 . 0 4 5}$ & $\mathbf{1 1 . 1 0 2 . 7 6 3}$ & $\mathbf{1 0 0 , 0 0}$ & $\mathbf{1 0 0 , 0 0}$ \\
\hline
\end{tabular}

Fonte: BRASIL. Ministério do Desenvolvimento Social - MDS, 2010. Elaborado pelos autores.

A análise por região aponta disparidades. Isto porque o Nordeste configura-se como a segunda maior região do país, com $27,99 \%$ da população total. Todavia, detém quase metade $(49,53 \%)$ do total da pobreza brasileira, destacando-se como a região mais pobre. Já a Região Sudeste, que possui a maior população (42,26\%), aparece com $26,98 \%$ da pobreza nacional, ou em segundo lugar no ranking do número de famílias pobres.

O que se constata é um desequilíbrio entre a população total de cada região e o número de famílias pobres, com o Nordeste e o Norte apresentando os maiores números ou percentuais de pobres na comparação com a sua população total. Por outro lado, 
as demais regiões (Sudeste, Sul e Centro-Oeste) apresentam, na distribuição regional, menor número de famílias pobres quando este é relacionado ao tamanho/peso de sua participação na população nacional.

Para Barros, Henriques e Mendonça (2001, p. 2):

pobreza não pode ser definida de forma única e universal, contudo, a pobreza refere-se a situações de carência em que os indivíduos não têm acesso a um padrão mínimo de vida condizente com as preferências socialmente estabelecidas em cada contexto histórico.

É preciso destacar que a distribuição de renda é apenas um segmento de mensuração da desigualdade, que apresenta um quadro muito mais amplo. Bourdieu (1998) alerta que o campo social constitui-se num espaço multidimensional bem mais amplo. Aliás, Dedecca (2009) enfatiza o tema e propõe a construção de uma abordagem de natureza multimensional para as estratégias de políticas públicas de combate à desigualdade, dado que os organismos multilaterais como a ONU (The Inequality Predicament), a OIT (Equality at Work) e a OECD (Growing Unequal?) indicam o crescimento da desigualdade socioeconômica mundial.

Diante desses resultados, com o Nordeste brasileiro concentrando quase metade do número de famílias pobres do país (49,53\%), com 5.499.039 de suas famílias vivendo na pobreza, o estudo foca-se na análise dessa região, notadamente nas especificidades dos seus nove estados.

Conforme mostram as Tabelas 1 e 2, dos 191.481.045 habitantes que residem no Brasil, o Nordeste possuía uma população total de 53.591.299 milhões (27,99\%) de residentes. O estado da Bahia, sendo o mais populoso da região (14.637.500 milhões), contribui com 7,64\% da população do território nacional. 
Pernambuco, Ceará e Maranhão são o segundo, terceiro e quarto maiores estados nordestinos, perfazendo, respectivamente, 4,60\%, $4,46 \%$ e 3,33\% do contingente populacional do país. Os demais estados da região participam, cada um, com menos de $2 \%$ na população total do Brasil.

\section{TABELA 2 - Estimativa da população e estimativa de famílias pobres, segundo estados da Região Nordeste - 2009}

\begin{tabular}{|c|c|c|c|c|}
\hline Estado & $\begin{array}{c}\text { Estimativa da } \\
\text { População em } \\
\mathbf{2 0 0 9}\end{array}$ & $\begin{array}{c}\text { Estimativa de } \\
\text { Famílias Pobres } \\
\text { (IPEA 2004) }\end{array}$ & $\begin{array}{c}\text { \% Estimativa } \\
\text { da População } \\
\text { em 2009 em } \\
\text { Relação à } \\
\text { População do } \\
\text { Brasil }\end{array}$ & $\begin{array}{c}\text { \% da } \\
\text { Estimativa } \\
\text { de Pobres* } \\
\text { (IPEA 2004) } \\
\text { em Relação } \\
\text { à População } \\
\text { Total Pobre } \\
\text { (2004) }\end{array}$ \\
\hline Alagoas & 3.156 .101 & 360.317 & 1,65 & 3,25 \\
\hline Bahia & 14.637 .500 & 1.408 .210 & 7,64 & 12,68 \\
\hline Ceará & 8.547 .750 & 896.882 & 4,46 & 8,08 \\
\hline Maranhão & 6.367 .111 & 718.909 & 3,33 & 6,48 \\
\hline Paraíba & 3.769 .954 & 395.090 & 1,97 & 3,56 \\
\hline Pernambuco & 8.810 .318 & 909.028 & 4,60 & 8,19 \\
\hline Piauí & 3.145 .164 & 352.128 & 1,64 & 3,17 \\
\hline Rio G Norte & 3.137 .646 & 291.160 & 1,64 & 2,62 \\
\hline Sergipe & 2.019 .755 & 167.315 & 1,05 & 1,51 \\
\hline Total NE & 53.591 .299 & 5.499 .039 & 27,99 & 49,53 \\
\hline
\end{tabular}

Fonte: BRASIL. Ministério do Desenvolvimento Social - MDS, 2010. Elaborado pelos autores.

No tocante ao número de famílias pobres, diferentemente da avaliação feita por regiões, a análise entre os diversos estados do Nordeste apresenta distribuição "justa/equitativa”: número de famílias pobres proporcional ao tamanho/peso da população de cada estado. Ou seja, o estado de Sergipe, que tem a menor população do Nordeste (2.019.755 milhões), é o que apresenta o menor número de famílias pobres $(1,51 \%)$ da região. Essa dinâmica é observada para todos os demais estados. 
Outro ponto que se destaca na Tabela 2 é que todos os estados do Nordeste possuem relativamente mais famílias pobres do que a sua contribuição no tamanho da população nacional. A Bahia, por exemplo, possui $7,64 \%$ da população do país, no entanto, detém 12,68\% da pobreza nacional. Esse resultado "era esperado", dado que o Nordeste, com $27,99 \%$ da população brasileira, possuía $49,53 \%$ das famílias pobres do país, uma diferença de $21,54 \%$ entre a sua população e o número de famílias pobres. Isso aponta para uma distribuição desproporcional entre os seus estados.

\section{Evolução dos programas federais de transferência de renda - 2004-2009}

Com o intuito de averiguar a evolução dos programas de transferência de renda do Governo Federal, especialmente os programas remanescentes e o Programa Bolsa Família (PBF), esta seção procura acompanhar o número de beneficiários e o volume dos recursos gastos com estes programas nos estados nordestinos.

O país, e especialmente a Região Nordeste, nos últimos anos tem sido alvo de medidas de combate à pobreza a partir de políticas sociais focalizadas nos mais necessitados.

Número de beneficiários dos programas remanescentes e do Bolsa Família

Apesar do Programa Bolsa Família (PBF) ter sido criado, em outubro de 2003, com a função de integrar em um único programa o Bolsa Escola (2001) e o Bolsa Alimentação (2001), juntamente com Auxílio Gás (2002) e o Cartão Alimentação (2003), em dezembro de 2004 o número de famílias pobres beneficiadas com estes programas remanescentes, no país, ainda somava 8.560.400, com $48,22 \%$ delas residentes no Nordeste. 
Gradativamente, observa-se que o número total de beneficiados com os programas remanescentes diminui a sua cobertura. Em 2006, apenas 712.735 famílias são assistidas com os programas, sendo que 366.314 (51,40\%) na Região Nordeste. Já em 2009, o número de beneficiados cai para 9.144 famílias, com $8.157(89,21 \%)$ residentes no Nordeste, enquanto o restante do país detém apenas $10,87 \%$ ou 987 famílias.

A análise estadual mostra que, em 2004, a Bahia, por ser a região mais populosa e com o maior número de pobres do Nordeste (Tabela 3), tinha 1.147.019 de famílias cadastradas em programas remanescentes $(13,40 \%)$, destacando-se com o maior número de famílias beneficiadas na região. Em seguida, aparecem o Ceará (8,61\%), Pernambuco (6,74\%) e Maranhão (6,36\%). Nessa lógica, o estado de Sergipe, com a menor população e o menor número de famílias pobres do Nordeste, apresenta também a menor quantidade de famílias (123.079) cadastradas nos programas remanescentes $(1,44 \%)$.

\section{Tabela 3 - Programas remanescentes* - evolução no número de famílias beneficiadas Brasil e UFs do Nordeste - anos selecionados - 2004/2009}

\begin{tabular}{|c|c|c|c|c|c|c|c|c|}
\hline \multirow{2}{*}{ Local } & \multicolumn{2}{|c|}{2004} & \multicolumn{2}{|c|}{2006} & \multicolumn{2}{|c|}{2008} & \multicolumn{2}{|c|}{2009} \\
\hline & Abs & $\%$ & Abs & $\%$ & Abs & $\%$ & Abs & $\%$ \\
\hline Alagoas & 208.217 & 2,43 & 14.180 & 1,99 & 5.870 & 2,44 & 172 & 1,88 \\
\hline Bahia & 1.147.019 & 13,40 & 80.270 & 11,26 & 29.814 & 12,37 & 1.832 & 20,03 \\
\hline Ceará & 737.087 & 8,61 & 60.717 & 8,52 & 22.506 & 9,34 & 1.660 & 18,15 \\
\hline Maranhão & 544.260 & 6,36 & 25.218 & 3,54 & 25.218 & 10,46 & 233 & 2,55 \\
\hline Paraíba & 260.124 & 3,04 & 60.717 & 8,52 & 23.087 & 9,58 & 668 & 7,31 \\
\hline Pernambuco & 576.696 & 6,74 & 64.308 & 9,02 & 27.846 & 11,55 & 2.159 & 23,61 \\
\hline Piauí & 291.787 & 3,41 & 27.448 & 3,85 & 10.072 & 4,18 & 537 & 5,87 \\
\hline $\begin{array}{l}\text { Rio G. do } \\
\text { Norte }\end{array}$ & 239.788 & 2,80 & 25.772 & 3,62 & 12.075 & 5,01 & 745 & 8,15 \\
\hline Sergipe & 123.079 & 1,44 & 7.684 & 1,08 & 2.723 & 1,13 & 151 & 1,65 \\
\hline
\end{tabular}




\begin{tabular}{l|c|c|c|c|c|c|c|c|}
\multirow{3}{*}{ Local } & \multicolumn{2}{|c|}{2004} & \multicolumn{2}{c|}{2006} & \multicolumn{2}{c|}{2008} & \multicolumn{2}{|c|}{ (conclusão) } \\
\cline { 2 - 10 } & Abs & \% & Abs & \% & Abs & \% & Abs & $\%$ \\
\hline Restante BR & 4.432 .343 & 51,78 & 346.421 & 48,60 & 81.787 & 33,94 & 987 & 10,79 \\
Total & 8.560 .400 & 100,00 & 712.735 & 100,00 & 240.998 & 100,00 & 9.144 & 100,00 \\
\hline
\end{tabular}

F onte: BRASIL. Ministério do Desenvolvimento Social - MDS, 2010. Elaborado pelos autores.

* Inclui Auxílio Gás, Cartão Alimentação, Bolsa Alimentação, Bolsa Escola.

Todavia, em 2009, a evolução no número de famílias beneficiadas não segue a lógica - tamanho da população vis-à-vis o número de pobres, dado que Pernambuco é o estado que detém o maior número de famílias $(23,61 \%)$ ainda recebendo os programas remanescentes, com 2.159 famílias cadastradas, contra 1.832 da Bahia. Mas, ao longo da série é possível observar a significativa diminuição no número de famílias beneficiadas com os programas remanescentes em todo o país, sendo o processo mais lento para a Região Nordeste, com destaque para o estado do Pernambuco.

Por outro lado, no caso do Programa Bolsa Família (PBF), verifica-se que à medida que diminui o número de beneficiários com os programas remanescentes (Tabela 3), este programa expande o número de famílias pobres atendidas em quase $100 \%$, ao passar de 6.571.839 em 2004 para 12.472.540 de famílias assistidas em 2009 (Tabela 4), o que representa aproximadamente 50 milhões de pessoas se considerarmos uma média de quatro indivíduos por família, correspondendo a aproximadamente $27 \%$ da população brasileira atendida pelo Bolsa Família no ano de 2009.

O Nordeste que, em 2004, tinha 3.186.344 de famílias cadastradas no PBF (48,48\%), em 2009 atinge um total de 6.240.750 de famílias assistidas, indicando que metade (50,04\%) das famílias pobres beneficiadas com o PBF localiza-se no Nordeste. Em outras palavras, de cada dez famílias assistidas com esse programa, cinco estão nessa região. Essa distribuição, conforme aponta a Tabela 1 , justifica-se em função do Nordeste concentrar aproximadamente $50 \%$ das famílias pobres do Brasil $(49,53 \%)$. 


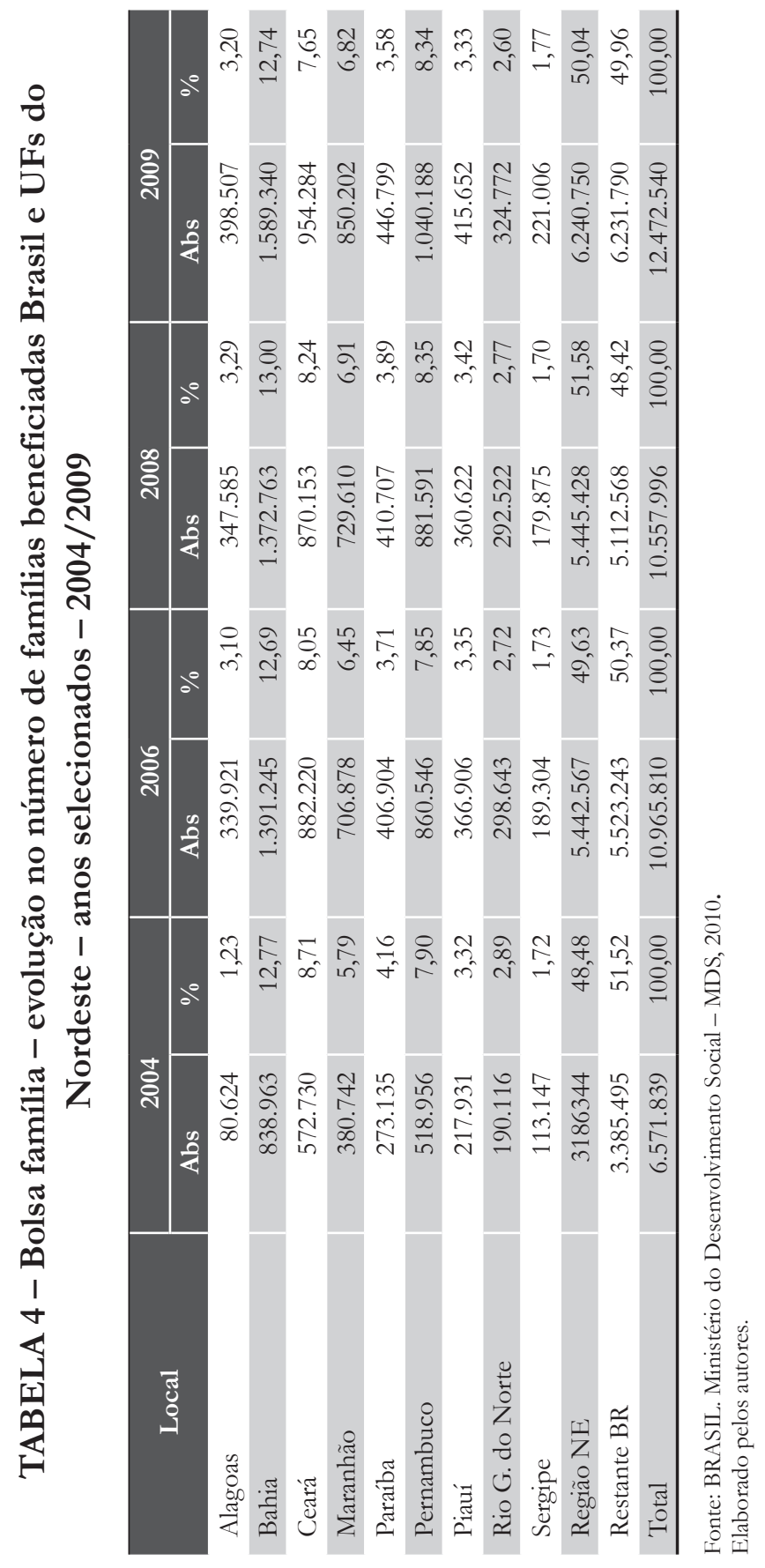


A abordagem estadual mostra pequenas alterações. Entre 2004 e 2009, todos os estados nordestinos tiveram aumento no número absoluto de famílias beneficiadas com o Bolsa Família (Tabela 4). Alagoas é o estado que indica, em termos percentuais, o maior incremento no número de famílias assistidas com o PBF, ao passar de 80.624 famílias (1,23\%), em 2004, para 398.507 famílias assistidas (3,20\%) em 2009 .

Vale ressaltar que o estado da Bahia detém o maior percentual $(12,74 \%)$ de famílias beneficiadas em toda a série, e Sergipe, por outro lado, mantém o menor número de beneficiários $(1,77 \%)$. Esses dois estados, juntamente com o Piauí, tiveram as menores oscilações, em termos percentuais, ao longo dos anos em questão.

As maiores oscilações/perdas relativas, entre os anos de 2004 e 2009, foram para o Ceará (de 8,71\% em 2004 para 7,65\% em 2009), a Paraíba (passa de 4,16\% em 2004 para 3,58\% em 2009) e o Rio Grande do Norte (de 2,89\% em 2004 para 2,60\% em 2009). Por sua vez, Alagoas, Maranhão e Pernambuco foram os estados que aumentaram a sua participação relativa no PBF, acompanhando a tendência da Região Nordeste, que passou de $48,48 \%$ em 2004 para 50,04\% em 2009.

Evolução no valor do repasse dos programas federais de transferência de renda

A análise da evolução dos gastos do Governo Federal com os programas de transferência de renda se faz importante, na medida em que tais programas têm sido alvo de elogios por alguns setores e criticado por outros.

Com a unificação dos programas remanescentes (Auxílio Gás, Bolsa Escola, Cartão Alimentação e Bolsa Alimentação), e a 
consequente redução significativa no número de famílias pobres beneficiadas com estes programas, observa-se, como era de se esperar, tendência de queda no volume dos recursos destinados (Tabela 5). No Brasil, o montante alocado para os programas remanescentes cai de $\mathrm{R} \$ 1.752 .348 .220$ em 2004 para $\mathrm{R} \$ 7.125 .495$ em 2009.

Do volume total de $\mathrm{R} \$ 7.125 .495$, o Nordeste, em 2009, concentra $\mathrm{R} \$ 5.994 .725$ ou $84,13 \%$ do valor dos recursos, apresentando, portanto, maior demora no processo de integração entre os programas remanescentes e o Bolsa Família. O restante do país, entretanto, fica apenas com 15,87\% do valor dos benefícios, o que aponta para maior agilidade na unificação dos programas.

Seguindo a tendência nacional e regional, é nítida a diminuição no volume repassado aos programas remanescentes em todos os estados da Região Nordeste ao longo da série: Pernambuco (23,10\%), Bahia (20,49\%) e Ceará (13,09\%) detêm, em 2009, mais de 50\% do volume total dos recursos destinados a esses programas, apontando para a delonga, nesses estados, na implementação da mencionada unificação dos programas remanescentes com o Programa Bolsa Família.

No tocante à evolução no valor do repasse destinado ao Bolsa Família, como era esperado, a partir da integração com os programas remanescentes, o acumulado no valor do benefício passa de $\mathrm{R} \$ 3.791 .785 .038$ em 2004 para $\mathrm{R} \$$ 11.280.436.305 em 2009, com o maior montante, 52,73\% ou $\mathrm{R} \$$ 5.947.713.646, destinado à Região Nordeste. Apesar do significativo aumento dos gastos com o PBF e das críticas de alguns setores, este programa é barato, pois não chega a $0,4 \%$ do PIB brasileiro e, por meio dele, acabam sendo injetados mais recursos na economia, a partir do consumo das famílias mais pobres. 


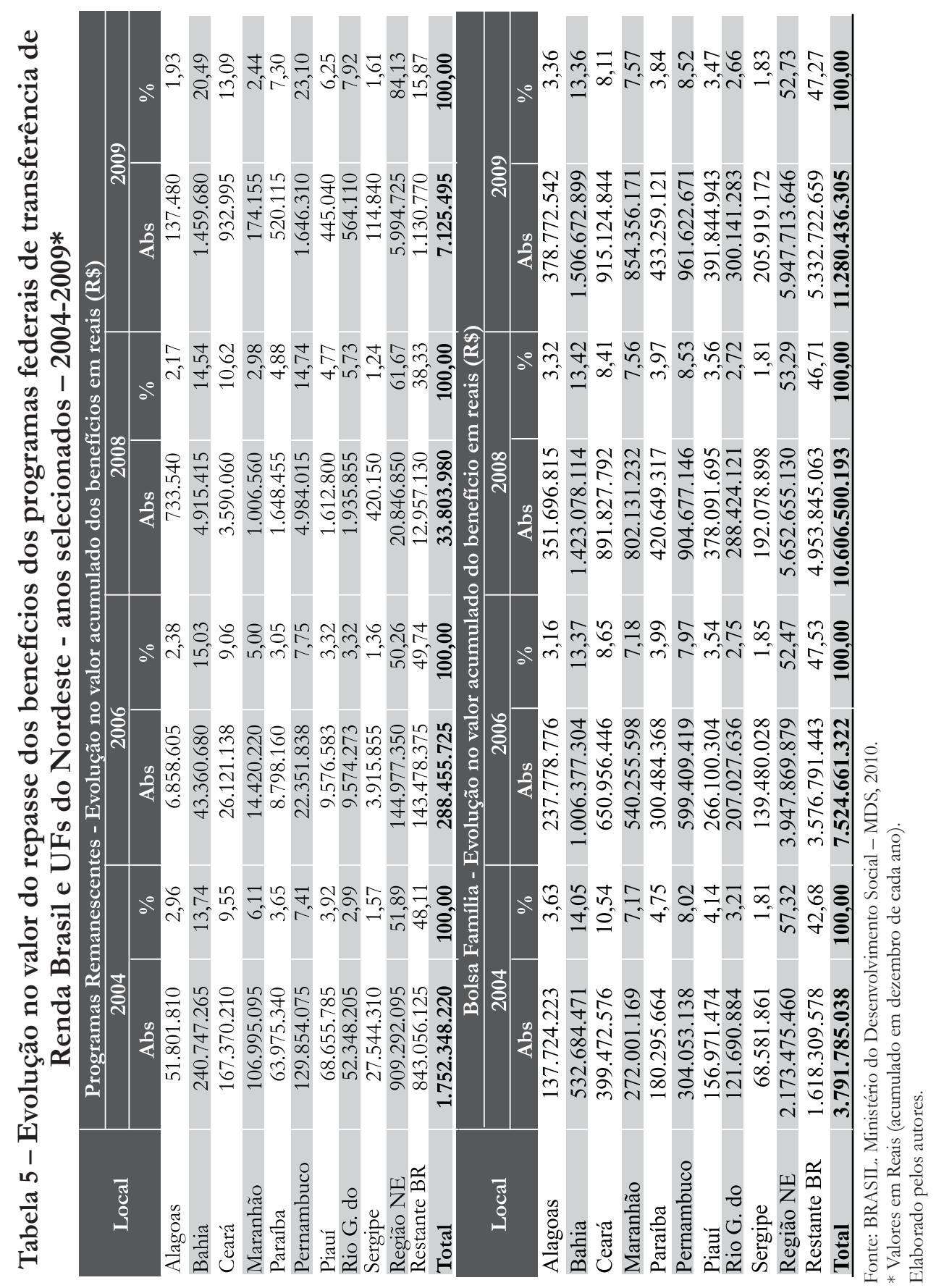


Um programa com ótima focalização também permite um impacto forte sobre a desigualdade com custo fiscal reduzido. Ou seja, os PTCRs [Programas de Transferência Condicionada de Renda] são um meio altamente custo-efetivo para a redução da desigualdade de renda, como demonstram os casos do Brasil e do México. Mas mesmo nesses países, nos quais os PTCRs atingiram uma escala que permite influenciar a distribuição de renda, seu peso na renda total ainda é bastante reduzido. Isto quer dizer que é possível expandir a cobertura e/ou o valor dos benefícios e obter impactos ainda maiores sobre a desigualdade. (SOARES et. al., 2007, p. 25)

Vale frisar que os autores anteriormente citados apontam para a importância dos programas de transferência de renda na redução da pobreza. Mas, esclarecem que tais programas têm limites fiscais e administrativos, e os mesmos não devem ser utilizados como principal mecanismo de combate à desigualdade, e sim conjugados com políticas de geração de emprego e correções das aposentadorias e pensões, dado o alto peso do rendimento do trabalho e da previdência social na distribuição da renda total do país (SOARES et. al., 2007).

Grande parte da crítica ao Bolsa Família refere-se à preocupação com os gastos públicos. Entretanto, quando comparados os gastos do Programa Bolsa Família com os juros da dívida em 2008, encontra-se 0,38\% do PIB para o Programa Bolsa Família e 6\% (R $\$ 162$ bilhões $^{8}$ em 2008) para os juros, de acordo com o BACEN. É preciso enfatizar que, em 2008, o Bolsa Família beneficiou 10.557.996 de famílias pobres no país, sendo que 51,58\% (5.445.428) delas na Região Nordeste.

Apesar das críticas às políticas de combate à pobreza mediante a concessão de renda, esses programas, juntamente com a estabilização da economia, o aumento real do salário mínimo e a queda dos juros a partir de 2004, têm reduzido a pobrez̧a no Brasil, conforme indica o relatório da Organização das Nações Unidas:

8 Comunicado da Presidência, n. 22, IPEA, 2009. 
No Nordeste também houve um declínio maior da miséria. A redução da diferença das taxas de pobreza extrema entre a região e o Sudeste, por exemplo, foi de 59\%. Em 1993, era de 18,2 pontos percentuais, e, em 2005, 7,5 pontos. Dada a dimensão da pobreza extrema no Nordeste, para que a taxa brasileira continue a cair no mesmo ritmo é indispensável que o país mantenha a queda acelerada na região. Assim, é importante garantir, como nos últimos anos, uma rede de proteção social fortalecida e o aprimoramento de ações de desenvolvimento regional. (PROGRAMA DAS NAÇÕES UNIDAS PARA O DESENVOLVIMENTO, 2007)

A análise estadual também indica, em números absolutos, aumento no valor do repasse do Programa Bolsa Família para todos os estados do Nordeste. A distribuição percentual mostrase quase inalterada ao longo da série, especialmente a partir de 2006. A Bahia, mais uma vez, se destaca ao receber $13,36 \%$ da distribuição nacional do PBF. Pernambuco com 8,52\%, seguido pelo Ceará $(8,11 \%)$ e o Maranhão $(7,57 \%)$. Na verdade, a distribuição do valor dos recursos dos programas é feito a partir do número de beneficiários.

O relatório da ONU também aponta resultados positivos sobre os indicadores sociodemográficos do país:

A diminuição da porcentagem de pessoas que ganham menos de US 1 dólar por dia foi acompanhada da redução das desigualdades em vários níveis. A pobreza caiu mais entre os pretos e pardos do que entre os brancos, por exemplo. Em 1993, 15\% dos negros viviam em situação de pobreza extrema e, em 2005, a porcentagem caiu para $6 \%$. No mesmo período, os números recuaram de $4,9 \%$ para 2,5\% entre os brancos. Apesar dos avanços, a miséria ainda atinge mais os negros. Em 2005, os brancos representavam 88,4\% do topo da pirâmide brasileira e $26,5 \%$ do décimo mais pobre. Já os negros eram 73,5\% dos mais pobres e apenas 11,6\% dos mais ricos. (PROGRAMA DAS NAÇÕES UNIDAS PARA O DESENVOLVIMENTO, 2007) 
Em estudo que procura analisar o papel dos programas de transferência de renda sobre a evolução dos indicadores da desigualdade no Brasil, México e Chile, Soares et al. (2007, p. 5) conclui:

O principal resultado obtido foi a evidência de que os PTCRs [Programas de Transferência Condicionada de Renda] contribuíram decisivamente para a redução da desigualdade nesses países entre meados dos anos 1990 e meados da primeira década do novo milênio. Os PTCRs são responsáveis por uma parte muito pequena da renda total, medida pelas pesquisas amostrais, em cada país: pouco menos que um por cento no México e no Brasil [...] No entanto, como a focalização dos PTCRs é ótima, o impacto sobre a desigualdade equivale a $21 \%$ da queda de 2,7 pontos de Gini observada tanto no Brasil como no México.

\section{Considerações finais}

Os programas transferência de renda vêm se consolidando como uma ferramenta auxiliar no combate e redução da pobreza, a despeito das críticas de alguns setores da sociedade. A proteção social avançou no Brasil a partir dos anos 2000. Os avanços se referem ao aumento no número de famílias assistidas e no valor do montante gasto com esses programas, além de alterações na concepção dos principais programas de transferência de renda do Governo Federal. Dentre os inúmeros programas sociais existentes no país, o Programa Bolsa Família destaca-se por sua cobertura e montante gasto.

O Bolsa Família, criado em outubro de 2003, passou a unificar em um só cartão os programas Bolsa Escola, Cartão Alimentação, Bolsa Alimentação e Auxílio Gás, tornando-se, desde então, o principal programa de transferência de renda do Governo Federal. Essa fase de transição foi importante, pois uma mesma pessoa poderia ter até quatro cartões. 
Nesse sentido, foi possível observar aumento significativo no montante gasto com o Programa Bolsa Família e no número de famílias cadastradas. O PBF em cinco anos de funcionamento sofreu expansão de aproximadamente 5,9 milhões de novas famílias assistidas em todo o país, perfazendo um total de aproximadamente 12,5 milhões de famílias pobres beneficiadas, representando um gasto de $\mathrm{R} \$ 11,3$ bilhões em 2009.

A análise regional indica que o Nordeste, região com os piores indicadores sociais e demográficos do país, foi o mais beneficiado com o Programa Bolsa Família, ao deter 52,73\% dos recursos gastos com esse programa e alcançar 6,2 milhões de famílias $(50,04 \%)$ em situação de pobreza ou extrema pobreza em 2009. A Bahia é o estado do Nordeste que contempla o maior número de famílias cadastradas no programa e consequentemente é a UF que recebe mais recursos. Vale frisar que a expansão no número de famílias atendidas com o PBF é calculada a partir de estimativas do número de famílias pobres em relação à população total do país, estado ou município.

Apesar da importância e dos impactos positivos dos programas de transferência renda, esses não devem ser vistos como a única ou a principal medida para retirar a população da situação de extrema pobreza ou pobreza. O governo deve criar políticas e oportunidades de emprego para a população, tornando-a capaz de garantir o seu próprio sustento, e assim deixar de receber benefícios de programas sociais.

Submetido em 30 de maio de 2010 e aceito para publicação em 14 de novembro de 2010 . 


\section{Referências}

ARAUJO T. B. Celso Furtado, o Nordeste e a construção do Brasil. In: ALENCAR JUNIOR, J. (Org.). Celso Furtado e o Desenvolvimento Regional. Fortaleza: Banco do Nordeste do Brasil, 2005.

BARROS, R. P.; HENRIQUES, R.; MENDONÇA, R. A estabilidade inaceitável: desigualdade e pobreza no Brasil. Rio de Janeiro: IPEA, 2001. (Textos para discussão, n. 800).

BOURDIEU, P. O Poder Simbólico. Rio de Janeiro: Bertrand Brasil, 1998.

BRASIL. Ministério do Desenvolvimento Social. Secretaria de Avaliação e Gestão da Informação. Matriz de Informação Social. Disponível em: $<$ http://aplicacoes.mds.gov.br/sagi/mi2007/home/login.php> Acesso em: 22 jan. 2010.

- Ministério do Trabalho e Emprego. Conselho Nacional de Imigração - CNIg.

. Presidência da República. Lei no 8.742, de 12 de Dezembro de 1993. Dispõe sobre a origem da Assistência Social.

BRASIL. Presidência da República. Lei no 10.219, de 11 de Abril de 2001. Institui o Programa Bolsa Escola.

. Presidência da República. Lei no 3.877, de 24 de Julho de 2001. Institui o Cadastro único.

. Presidência da República. MP no 2206.1, de 6 de Setembro de 2001. Institui o Bolsa Alimentação.

. Presidência da República. Lei no 10.453, de 13 de Maio de 2002. Institui o Programa Auxílio Gás.

- Presidência da República. Lei no 10.689, de 13 de Junho de 2003. Institui o Cartão Alimentação.

- Presidência da República. Lei no 10.836, de 9 de Janeiro de 2004. Institui o Programa Bolsa Família.

PROGRAMA DE GARANTIA DE RENDA MÍNIMA. Projeto de Lei da Câmara nº 2561, de 1992, (PLS 80/91). Disponível em: <http:/www.senado.gov.br/eduardosuplicy/Programa/projeto_ lei.asp>. Acesso em: 18 mar. 2010. 
CANO, W. Raizes da concentração industrial em São Paulo. São Paulo: Difel, 1977.

. Desequilíbrios regionais e concentração industrial no Brasil. São Paulo: Global, 1985.

DEDECCA, C. S. Desigualdade, mas de qual falamos? Campinas: UNICAMP, 2009. (Textos para discussão, n. 168). Disponível em: < http://www. eco.unicamp.br/publicacoes/index.php?itemID $=$ TextosDiscussao $>$. Acesso em 20 fev. 2010.

DINIZ, C. C.; CROCCO, M. A. Reestruturação econômica e impacto regional: o novo mapa da indústria brasileira. Nova Economia, Belo Horizonte, v. 6, n. 1, jul. 1996.

FONSECA, A. M. M. O debate sobre familia e a política de renda minima. 2000. Tese (Doutorado em História Social) - Universidade de São Paulo, São Paulo, 2000.

INDICADORES DE POBREZA. Disponível em: <http://www. un.org./esa/socdev/unyin/documents/ydiDavidGordon_poverty.pdf $>$. Acesso em 23 fev. 2010.

INSTITUTO DE PESQUISA ECONÔMICA APLICADA. Receita pública: quem paga e como se gasta no Brasil. Brasília, 2009. (Comunicado da Presidência, n. 22) Disponível em: < http://www.ipea.gov. br/003/00301009.jsp?ttCD_CHAVE=10658>. Acesso em: $17 \mathrm{fev}$. 2010.

ORGANIZAÇÃO DAS NAÇÕES UNIDAS. Declaração do Milênio. Cimeira do milênio. Nova Iorque, 6-8 set. 2000. Disponível em: <http:// www.pnud.org.br/odm/\#>. Acesso em: 18 mar. 2010.

PACHECO, C. A. Fragmentação da Nação. Campinas: Unicamp, 1998.

PEREIRA, J. M. P. D. Programa bolsa familia: exploracõos sobre as visões de seus executores e beneficiários. 2008. Trabalho de Conclusão de Curso (Monografia) - Departamento de Antropologia, Universidade de Brasília, 2008.

PROGRAMA DAS NAÇÕES UNIDAS PARA O DESENVOLVIMENTO. Brasil redur pobreza extrema pela metade e cumpre ODM, diz ONU. Brasília, 29 ago. 2007. Disponível em: < 
http://www.pnud.org.br/pobreza_desigualdade/reportagens/index. php?id01=2759\&lay=pde> . Acesso em: 17 mar. 2010.

RIBAS, R. P. Determinantes do risco de pobreza urbana no Brasil durante a década de 90. Belo Horizonte: UFMG/Cedeplar, 2005. (Textos para discussão, n. 266).

ROCHA, S. Pobreza no Brasil: afinal do que se trata? Rio de Janeiro: FGV, 2005.

RODRIGUES, E. V., et. al. A pobreza e a exclusão social: teoria, conceitos e políticas sociais em Portugal. Revista da Faculdade de Letras, Porto, série I, v. 09, 1999.

SOARES, S., et. al. Programas de transferência condicionada de renda no Brasil, Chile e México: impactos sobre a desigualdade. Brasília: IPEA, TD n. 1293, 2007.

WOLLF, E. W. Poverty and Income Distribution. Chichester: WileyBlackwell\&Sons, 2009. 